Rev. SINAPSIS, Edición № 9, Vol. 2, Diciembre 2016

ISSN 1390 - 9770

\title{
Cuerpos políticos y políticas sobre el cuerpo en las dictaduras latinoamericanas
}

\section{Cuerpo y política en dictaduras latinoamericanas}

\author{
Eleder Piñeiro Aguiar. PhD ${ }^{(1)}$
}

(1) Universidad San Gregorio, Ecuador

Contacto: elederpa1983@gmail.com

Receptado: 19/09/2016 Aceptado: 15/11/2016

\section{Resumen}

Por medio del análisis de contenido se propone relacionar la teorización que desde diversas fuentes académicas se ha venido realizando en torno al cuerpo con momentos históricos del pasado reciente en Latinoamérica, en concreto en periodo dictatoriales. Se propone una revisión de la tortura y la desaparición como elementos centrales en la construcción nacional y en la formación capitalista; así como el uso y producción de discursos en torno al cuerpo como resistencias frente al orden estatal que ha venido imponiendo la violencia en el contexto de diferentes dictaduras en países de América del Sur. Rastrearemos la producción científica para entender el cuerpo humano como algo social y simbólicamente construido y expondremos mediante un recorrido histórico ciertos estudios de caso. En dichos casos el ejercicio de suplicios, malos tratos y vejaciones han servido para generar dinámicas de poder-resistencia en torno a la persona, no vista desde un punto de vista individual o psicológico sino social, relacional y en construcción.

Palabras clave: tortura, resistencia, violencia, neoliberalismo, América Latina

\section{Political and politicians bodies in the Latin American dictatorships}

\begin{abstract}
Through content analysis it is proposed relate theorizing from various academic sources has been carried around the body with historical moments of the recent past in Latin America, particularly in dictatorial period. A review of torture and disappearance as central elements in national construction and the

\footnotetext{
${ }^{1}$ Universidad San Gregorio de Portoviejo, Ecuador
} 


\section{Rev. SINAPSIS, Edición №9, Vol. 2, Diciembre 2016}

capitalist formation is proposed; and the use and production of speeches around the body as resistance against the state order that has been imposed violence in the context of different dictatorships in countries in South America. We will track the scientific production to understand the human body as social and symbolically constructed and will discuss a historical journey through some case studies. In such cases the exercise of torture, ill-treatment and harassment have served to generate power dynamics-resistance around the person, not viewed from an individual or psychological but social, relational and construction sight.

Keywords: torture, resistance, violence, neoliberalism, Latin America

\section{Introducción}

Brujas quemadas en hogueras, traidores lapidados, marineros ahorcados, regicidas en el potro, siervos estirados en caballos, ladrones con manos cortadas o crucificados, minorías en cámaras de gas, violadores en sillas eléctricas, ahogamientos de bebés, expulsiones, invisibilizaciones, genocidios, violaciones, profanaciones de tumbas...La tortura, el sufrimiento, el martirio, el suplicio y otras formas de violencia son consustanciales a la formación del sistema-mundo tal como lo entendemos hoy en día. "La horca era el destino de una parte del proletariado, porqueera necesario utilizarla para la organización y el buen funcionamientode los mercados laborales transatlánticos, marítimos y de cualquier otrotipo, y para acabar con las ideas radicales" (Linebaugh y Rediker, 2005, p. 46),

Existen y han existido diferentes actos de violencia ejercidos por diferentes autoridades en aras del orden, paz social, el libre comercio, la seguridad o la libertad duradera."La tensión entre apropiación y violencia es particularmente compleja a causa de su relación directa con la extracción de valor (...) La humanidad moderna no es concebible sin la subhumanidad moderna" (Sousa Santos, 2010, p. 18).

No trataremos de exponer un relato histórico-nacional de estos y otros momentos político-sociales ni mucho menos trazar una genealogía de las dictaduras latinoamericanas. Nos interesa analizar cómo ciertos cuerpos políticos y politizados han entrado en contacto con el cuerpo estatal para generar categorías como son las del/de la torturado/a, del/de la desaparecido/a, del/la quebrado/a y del aguante. Y dentro de todo ello, a nivel local, a nivel micropolítico, la tortura.

La carrera política de varios dirigentes en Latinoamérica en los últimos años también está marcada por la violencia hacia sus cuerpos. La vida de Pepe Mújica, ex presidente de Uruguay, no puede 
Rev. SINAPSIS, Edición № 9, Vol. 2, Diciembre 2016

ISSN 1390 - 9770

comprenderse sin los 12 años ( 2 de los cuales en un foso tan grande como su propio cuerpo) que pasó como preso y torturado en la dictadura uruguaya (1976-1989). El padre de Michelle Bachelet fue torturado por el régimen de Pinochet hasta la muerte y a su hija también la tuvieron presa, donde vio cómo fueron violadas dos compañeras suyas. A Dilma Roussef también le aplicaron tortura, incluidas descargas eléctricas. Al recordarle su pasado como guerrillera, suele exponer que "cuando Brasil cambió, yo cambié".

¿Pero cómo, cuándo, cómo, por qué y para quién se recuerdan esos actos violentos? En toda construcción nacional y regional, la lucha por el presente es también lucha por los pasados que ese presente contiene. Toda historia contiene microhistorias, unas oficiales, otras invisibilizadas y con múltiples zonas grises e intersticiales entre ambas. "Si bien el desarrollo de Informes de Verdad por parte de los Estados ha constituido un paso importante en el reconocimiento y legitimación pública de las consecuencias de la violencia, paralelamente, se han sostenido políticas de olvido que han legitimado la impunidad de los responsables"(Chamorro \& Donoso, 2012, p. 52).

\section{Materiales y métodos}

Para el análisis propuesto nos serviremos tanto de la historia oficial como de ciertos relatos de algunos de los principales agentes involucrados. El contexto, digamos local, de esas identidades nos lo dará el análisis de la tortura y el denominado aguante/quiebre sufrido y vivido por diversos actores encontrado en diversas fuentes académicas y periodísticas. Hemos escogido estudios de caso de diferentes países encontrados en la red, con un análisis inicial del término "tortura" en google académico, arrojando más de 135.000; delimitando esto, el término “tortura Latinoamérica” arrojó más de 22.000 resultados.

Contextualizando más aún, y cruzando con fuentes en español provenientes de Latindex, Scielo, Dialnet y Redalyc, se escogieron ciertos casos como material de análisis en el apartado II, que se relaciona con la elaboración teórica del apartado dedicado a las teorías que diversos autores provenientes de la sociología, la historia, la antropología y la filosofía han realizado en torno a la definición del cuerpo y de la violencia.

\section{Resultados}


Rev. SINAPSIS, Edición № 9, Vol. 2, Diciembre 2016

ISSN 1390 - 9770

\section{I.- Algunas teorizaciones en torno al cuerpo, la violencia y el dolor}

Emile Durkheim mostró en El suicidio(1992) cómo las elecciones que un sujeto toma en su realidad social dependen de factores grupales mediados por lo cultural y lo social, no son individuales ni meramente psicológicas. Su yerno, Marcel Mauus (1979) consideraba una necesidad urgente analizar, describir e inventariar los usos que los hombres han hecho y hacen de su cuerpo. Reflejo, lugar de enunciación y horizonte donde se producen y se reproducen los retazos de esa historia, el cuerpo es un cronotropo de la política, marcando subjetividades e identidades, en una lectura bajtiniana (1989). Esto es, el tiempo y el espacio en los que se inserta el cuerpo son categorías de algún modo objetivables pero solo si se procede en un análisis intersubjetivo. No son aprioris sino que son generadas por la materialidad del mundo, o en este caso de la realidad política.

Mientras Gregory Bateson y Margaret Mead (1942) analizaron cómo los gestos y movimientos del cuerpo tienen que ver con el aprendizaje de una cultura socialmente aprendida e incorporada, Mary Douglas diferencia entre cuerpo físico y cuerpo social, afirmando que el segundo restringe al primero (Douglas, 1991). Asimismo Pierre Bourdieu (1986) expone que el cuerpo es un producto social y por lo tanto desnaturalizado si hablamos desde un punto de vista biológico

Dice Le Bretón del cuerpo que "pertenece, por derecho propio, a la cepa de identidad del hombre (...) Vivir consiste en reducir constantemente el mundo al cuerpo (...) El cuerpo es un elemento de gran alcance para un análisis que pretenda una mejor aprehensión del presente” (Le Bretón, 2002, p. 7). Es así que el cuerpo es un lugar simbólico, no solamente una realidad material. Es a la vez construcción, estado y acción. Hay que entenderlo más bien como una consecuencia que como una evidencia o una causa, si bien también puede servir, como veremos, a modo de prueba del pasado y de la historia.

Por su parte Michel Foucault (1990) expone que hace más de 200 años, el espectáculo del patíbulo es poco a poco dejado de lado por lo que él denomina sobriedad punitiva. La pena es cambiada por el cumplimiento de la ley y así un cuerpo es dócil cuando puede ser utilizado, transformado, domesticado, perfeccionado, analizado, manipulado. Cuando es útil y obediente. Asimismo el martirio es calculado, tiene intensidades, momentos, reglamentaciones, codificaciones, es controlado y administrado. La tortura puede estar plenamente estructurada y planificada, no es algo irracional o temperamental. 


\section{Rev. SINAPSIS, Edición №9, Vol. 2, Diciembre 2016}

La docilidad de los cuerposha sido buscada por múltiples dictaduras en Latinoamérica a lo largo de muchas décadas. Naomi Klein (2007) denomina "capitalismo del desastre" a las experiencias traumáticas vividas tanto por causas naturales como por causas humanas (guerras y golpes de estado principalmente). Estas le sirven a la economía para generar estados postraumáticos que le son muy útiles al neoliberalismo para reducir aún más el Estado de Bienestar e instaurar las doctrinas impulsadas por los Chicago Boys.

Para entender la labor que el Estado ejerce hacia sus ciudadanos, hemos de situar el plano de la violencia ejercido hacia la ciudadanía. Melgarejo y Matamoros (2013) realizan un resumen en torno a diferentes teorizaciones en torno a este concepto, desde Engels a René Girard, pasando por HannaArendt, Marx, Clastres, Norbert Elías, etc. Afirman que la violencia tiene más bien que ver con factores sociales y políticos que con biológicos o psicológicos. Las causas, características y consecuencias de la violencia presentan una gran variabilidad dependiendo factores sociales, culturales e históricos.

Por tanto tenemos en el cuerpo una realidad sociocultural y simbólica, en constante construcción, que sirve de cronotropo para entender lo político; por otra parte es un lugar donde las asimétricas fuerzas de la autoridad y la resistencia entablan sus relaciones de poder; además de ser un espacio de disciplinamientos y foco principal desde el que actúa y se (re)produce el capitalismo. El cuerpo es un lugar propicio desde el que ejercer violencia, que sirve como medio para fines tales como protegerse de enemigos, obtener información y estar protegidos.

\section{II.- Contextos globales en lo local}

Terminada la Segunda Guerra Mundial Latinoamérica se convierte en zona caliente del planeta, con los intereses EE.UU. y la URSS, abiertamente enfrentados. En 1946 se crea la Escuela de las Américas en Panamá. La Escuela entrenó a casi 60.000 soldados provenientes de 18 países, con fondos pagados de impuestos públicos. Según el departamento de Defensa USA, sus objetivos son promover la democracia y extender los derechos humanos, mediante la profesionalización militar. Entre algunos de sus graduados figuran: Manuel Noriega (expresidente de Panamá), Hugo Bánzer (exdictador de Bolivia), Héctor Gramajo (ExMinistro de defensa de Guatemala), Leopoldo Galtieri (exlíder de Junta argentino), entre otros. Entre los entrenamientos están: guerra de baja intensidad, operaciones psicológicas, contrainsurgencia, recopilación de información, métodos de interrogación (donde por supuesto figuraba la tortura). 
Rev. SINAPSIS, Edición № 9, Vol. 2, Diciembre 2016

ISSN 1390 - 9770

En 1963 la CIA elaboró un documento, encriptado bajo las siglas KUBARK, que serviría de base para proceder con los interrogatorios, donde no hay improvisación o libre albedrío. Entre las acciones del documento figuran: controlar psicológicamente, analizar personalidad, controlar miedos, inseguridades, pasiones, buscar debilidades donde el interrogado pueda caer, utilización de engaños y confusiones, amenazar, infringir dolor, suministrar drogas. Existe, además una burocracia de la tortura, pues dependiendo del caso ha de existir aprobación previa de las autoridades para infligir dolor, utilizar medicinas, químicos o electricidad, etc.

En 1983 la CIA emite otro documento denominado "Manual de entrenamiento para la explotación de los recursos humanos". Entre las acciones del mismo figuran la privación de sueño y comida, infligir o amenazar dolor, colocar a los prisioneros en posiciones incómodas durante periodos prolongados, aislamientos, vendar los ojos, etc. La mayoría de estos protocolos son llevados a cabo fuera de suelo estadounidense, entre otros lugares en Latinomérica. Nancy Schepper Hughes (1997, p. 25-26), hablando de la dictadura en Brasil, expone que

utilizaba torturas y amenazas de torturas, prisiones y exilios con el fin de forzar una apariencia de consenso popular y liberar el país de sus «peligrosos» demócratas y «subversivos» (véase Amnesty International, 1988, 1990). Mientras tanto, Estados Unidos mantenía abiertamente (con la excepción de los años de Carter) relaciones cordiales con los brutales dictadores, quienes se presentaban ante la opinión pública estadounidense como enemigos del comunismo y, por tanto, amigos de Estados Unidos.

Arresto, detención e interrogatorio anteceden a la tortura, que es vista como contexto y como proceso de la guerra que se está llevando a cabo, siendo el cuerpo del enemigo uno de los frentes de batalla.

\section{Discusión}




\section{Rev. SINAPSIS, Edición № 9, Vol. 2, Diciembre 2016}

Diana Ortiz, por ejemplo en Guatemala, contaba hasta con 111 quemaduras en su cuerpo ${ }^{2}$.

Uno de los testimonios más famosos de La dictadura en Chile lo tenemos en Nieves Ayres ${ }^{3}$, "presa política durante tres años bajo la dictadura de Augusto Pinochet, soportó torturas inenarrables que amenazaron con destruir su identidad física y sexual" (Kaplan, 2002, p. 179). La clave para su supervivencia fue la posibilidad de crear comunidad en su internamiento, encontrar confidentes y contar lo sucedido. El arma empleada, una vez liberadas, fue la declaración en torno a la tortura sufrida. Pero Ayres no esperó a salir, sino que contó su historia ya estando en prisión. Para ello, una de sus compañeras de celda, Inés Antúnez, que partió al exilio, guardó en su vagina el relato y se lo cedió a una organización en pro de los derechos. Uno de los órganos encargados de la reproducción biológica se transforma así en reproductor social e histórico, se "biolegitima" el cuerpo (Fassin, 2003). "Ninguna de las prácticas ni de los discursos de la resistencia pueden existir sin una coordinación y comunicación tácita o explícita dentro del grupo subordinado. Para que eso suceda, el grupo subordinado debe crearse espacios sociales que el control y la vigilancia de sus superiores no puedan penetrar" (Scott, 2003, p. 174)

Por tanto podemos observar que mientras el gobierno de Pinochet trató de avergonzar a Ayress y otras mujeres, privándolas de su sexualidad, humillándolas, insultándolas, violándolas, etc., el relato de esta activista feminista sirvió para derribar a la dictadura. La diferencia del testimonio, con respecto a otros, es que está centrada en torno a lo que le sucedió como mujer, rompiendo con la conspiración del silencio mayoritariamente conseguido en torno a las presas políticas encarceladas en decenas de países. Un relato, unido al de tantos otros, sirve para combatir el fascismo. El cuerpo, pues, es utilizado como herramienta de construcción nacional. En una ocasión, un miembro del $\mathrm{MIR}^{4}$ que también había sido torturado, relataba cómo estaba atado a un palo y colgado en horizontal entre sesiones de tortura. En una ocasión, le preguntó la hora a sus captores, ante lo cual estos continuaban insultándole y golpeando. Cuando en un descanso, al fin uno de ellos le dijo la fecha y el día, este preso político contestó: "Con razón estaba yo tan aburrido”. Era domingo. El humor es arma poderosa contra el poder (Bajtín, 1989).

\footnotetext{
${ }^{2}$ Consultado en http://www.cidh.org/annualrep/89.90span/cap4c.htm el 27 de mayo de 2016

3 Utilizamos para este testimonio el texto de Temma Kaplan: "Revertir la vergüenza y revelar el género de la memoria". Publicadooriginalmenteen Signs: Journal of women in Culture and society, Vol 28, Otoño 2002. Pgs. 179-200

${ }^{4}$ Movimiento de Izquierda Revolucionaria, fundado en 1965 y con activa presencia durante la dictadura pinochetista. Llegó a contar con 10.000 miembros.
} 


\section{Rev. SINAPSIS, Edición №9, Vol. 2, Diciembre 2016}

Esta persona dijo que peor que el dolor era el tiempo entre las sesiones del suplicio. Además del sufrimiento corporal, "se suma la angustia de la espera, la incertidumbre, lahumillación, el horror de estar sometido a una imaginaciónsádica sin control exterior, a voluntad de los torturadores” (Le Bretón, 1999, p. 249). Y el cuerpo debe ser de nuevo aprendido, domesticado, enseñado, pues las secuelas pueden ser muchas y no solo físicas (úlceras, dolores de cabeza, problemas respiratorios o gástricos) sino también psíquicas: miedo al contacto, a espacios vacíos, al ruido, al silencio, insomnio, pesadillas, manías persecutorias, hipocondrías, miedo al futuro, etc.

En el caso de Nieves Ayress fue violada en grupo y mutilada. Su padre y su hermano eran obligados testigos imposibilitados de hacer nada. A continuación, todos fueron colectivamente torturados. Y amenazaron con que obligarían a sus familiares a violarla. Simularon con matarlos. Asesinaron a otra persona delante de ellos. Tras 27 días de torturas, los trasladaron a un campo de concentración, donde sufrieron un mes más de tortura, incluida la picana eléctrica; le introdujeron roedores en la vagina, la colgaron de brazos y piernas; la obligaron a comer excremento; la sometieron sexualmente con hombres y perros; yacía sobre su sangre. Y recibía insultos, era ridiculizada.

"Las marcas en el cuerpo posibilitan probar la participación en gestas heroicas, a manera de un registro del pasado", exponen Alabarces y Garriga (2008, p. 282). Pero posibilitan también, en negativo, el (de)mostrar que la participación es un acto no deseado, involuntario, cuyo relato de heroicidad corre paralelo a la historia oficial sin llegar nunca a juntarse del todo. En ese sentido, el cuerpo marcado, al igual que la mente y el recuerdo, trazan una genealogía del lugar sociopolítico ocupado por la persona.

Asimismo la sexualidad se utilizaba, rompiéndola (o en la jerga, quebrándola), con el fin de socavar la dignidad, deshacer la identidad, establecer una imagen irreconocible para el propio sentido del yo. "La práctica de la dominación y de la explotación produce normalmente los insultos y las ofensas a la dignidad humana, que a su vez, alimenta un discurso oculto de indignación” (Scott, 2003, p. 31). En el discurso de los torturadores, eso no se enuncia así. A lo que se impele es a que el torturado colabore.

Muchos torturados sobrevivieron cantando para sí o hablándole a objetos inanimados. Una salida al dolor y al sufrimiento es crear espacios imaginarios. Se crea una identidad de resistencia, no racional o más bien a-rracional, siendo la narración de lo sucedido al cuerpo el arma política para cambiar el estado de cosas: "el pasado adquiere vigencia para presionar el presente en la construcción de identidad" (Pérez Taylor, 2013, p. 49). 


\section{Rev. SINAPSIS, Edición № 9, Vol. 2, Diciembre 2016}

Ya cuando fue liberadaAyress sufrió amenazas de muerte durante años. Aun así, logró resistir, ser testigo, generar comunidades de apoyo, superar la vergüenza y permitir una relación en el que muchas mujeres pudieron reconocerse en torno a testimonios similares. "La admisión del sufrimiento es difícil de enunciar porque comporta reconocer el éxito del torturador” (Le Bretón, 1999, p. 252). Pero a su vez, narrar la historia es una forma de acción directa en medio de un acto de biolegitimidad: "forma de reconocimiento social de la vida como bien supremo" (Fassin, 2003, p. 53).

Estos casos muestran que la dignidad no es solo personal sino que es una acto político, tanto individual como público. La palabra recuperada sirve no solo de curación psicoanalítica, sino de victoria política que por una parte retoma la existencia y por otra parte sirve de denuncia de las atrocidades cometidas en las que otros se pueden reflejar y hacer grupo ante la violencia estatal.

Otro ejemplo más del Cono Sur:en el año 1989 hubo en Uruguay un plebiscito que rompió la relación de ese país con su pasado reciente (Marchesi\&Markarian 2012). La dictadura allí comenzó el mismo año que la chilena y duró cinco años menos, hasta 1985. Al año siguiente, 1986, se creó la Ley de caducidad de la pretensión punitiva del estado, ley de caducidad o peyorativamente ley de impunidad. El plebiscito de1989 ratificó la Ley. En 2009, un nuevo plebiscito tampoco enjuició a los partícipes de la dictadura. Los delitos de lesa humanidad no fueron catalogados como tales hasta 2011, es decir, más de un cuarto de siglo después de finalizada la dictadura.Casi dos generaciones no pudieron ver esto.

En ese contexto Gilberto Vázquez ${ }^{5}$, coronel retirado que ejerció durante la dictadura en Uruguay, expone que "no hubo más remedio; la tortura era útil", a la vez que reconoce que con algunos se les fue de las manos. Alega que lo que estaba en juego era la vida de soldados y los intereses de la República: “cuando a uno le toca, tiene que elegir el mal menor. O los reventaba a palos o dejaba que siguieran matando a mis camaradas". En el caso de los desaparecidos alega cuestiones económicas, pues el Estado no tenía dinero para funerales; y también por temas de imagen exterior, pues Uruguay es destino turístico y da muy mala prensa hablar de muertes.

En ese sentidoafirmamos que no todos tenemos las mismas sensibilidades: "la relación íntima con el dolor depende del significado que éste revista en el momento en que afecta al individuo (Le Bretón, 1999, p. 9).La tortura supone un desmembramiento del cuerpo social por parte del cuerpo individual. Expone

\footnotetext{
${ }^{5}$ En http://www.180.com.uy/articulo/16708 No-hubo-mas remedio la tortura era util. Consultado 10/05/2016
} 


\section{Rev. SINAPSIS, Edición №9, Vol. 2, Diciembre 2016}

una falla en el sistema por haberse salido del camino de la rectitud moral, social o normativa. Y dicha falla debe ser reconducida. "El arte de hacer sufrir al otro para obligarlo, humillarlo o destruirlo es inagotable en sus realizaciones. El dolor infligido es el objeto de preferencia, hasta el arquetipo del ansia de poder sobre el otro" (Le Bretón, 1999, p. 9)

El cuerpo torturado es excluido de lo social y pasa a formar parte de una especie de comunidad Se inserta en un "nosotros" grupal que rompe necesariamente con el hilo argumental del individualismo occidental. La resistencia no es efectiva solamente porque la comunidad se imagina a sí misma (Anderson, 2006) sino porque es capaz de generar sentimientos de proyección hacia un futuro-otro. Allí, los límites impuestos por el Estado se derrumban. El contexto de creación de ese futuro alternativo se da a lo largo del cuerpo sufriente. El temor ante el vacío que supone la tortura, especialmente entre sesiones de la misma, es llenado con retazos de comunidad: pensar en la familia, imaginar distopías, recrear otros ambientes, evadirse a otros espacios.

Pero para entender el contexto de las dictaduras hemos de comprender también el de otra categoría política como es el de la persona desaparecida. No solamente remite a la ausencia de rastros y pistas del paradero de una persona buscada por sus familiares o conocidos, sino que también es el significante que condensa y vehiculiza la experiencia histórica del terrorismo de estado y las demandas de "memoria, verdad y justicia" por los delitos de lesa humanidad. (Varela \& González, 2015, p. 79). No hay estadísticas oficiales en torno a los desaparecidos. Los números que hay forman parte de un trabajo de ONGs, iglesias, asociaciones, instituciones públicas y privadas, escuelas, universidades. No hay, porque no puede haberlo, un conteo oficial.

Así como el cuerpo torturado está, aunque recluido y excluido, expuesto a una mensurabilidad; el cuerpo desaparecido es una especie de fantasma, un ente, un in-between(Bhabha, 2002) entre dos mundos, pues no se le puede dar por muerto (aunque se sospeche esto) ni puede terminar la búsqueda como un vivo, tal como por ejemplo las madres y abuelas de la Plaza de mayo vienen realizando durante décadas. Reclaman por los aproximadamente 30.000 desaparecidos, en su mayoría jóvenes; reclaman por los millones que fueron al exilio desde Argentina; reclaman, en fin, por una generación perdida. De hecho, llevan ya casi dos generaciones haciéndolo. "Se echaron a la plaza y, haciendo del cuerpo el primer escenario de performatividad (y recordándonos que toda voz se emite con un cuerpo), se reapropiaron del lenguaje que los había indignado" m expone CarlosDiz, 2013, p. 96-97 analizando las primaveras 
Rev. SINAPSIS, Edición № 9, Vol. 2, Diciembre 2016

ISSN 1390 - 9770

árabes y el movimiento de los indignados en España. En el caso argentino se trataría también de indignación y sentimiento de injusticia hacia un régimen que había desaparecido a hijos, nietos, sobrinos, hermanos, padres

"Tratamientos" parecidos se dieron en Paraguay, país del que Alfredo Boccia (2010, p., 75) expone al hablar de la dictadura de Stroessner (1954-1989) que "sabemos ahora mucho más de lo que sucedía en esos años que lo que sabían quienes vivieron ese tiempo." Dice Boccia que al no haber el pasado democrático-cívico en Paraguay, fue mucho más sencillo para el régimen eternizarse en el poder, exponiendo una versión democrática dócil hacia el exterior pero actuando de forma muy represiva al interior. Entre otras atrocidades, y apuntalados por un catolicismo y patriarcado normalizados a nivel estatal, "Stroessner y algunos de sus generales llevaban una vida de lascivia y abusos de niñas menores de edad" (ibid, p. 76) a la vez que mantenían una imagen de familia nuclear y matrimonio feliz, pero con varias amantes.

La invisibilización de violaciones, secuestros y muertes y la exhortación popular a "los queremos vivos" enmarca el doble temor que entraña la desaparición pues se exige: 1) que no los maten; 2) que vuelvan.

\section{Conclusiones}

El cuerpo sufriente, el cuerpo dócil, el cuerpo que se quiebra, el cuerpo que resiste, el cuerpo torturado, el cuerpo que aguanta, el cuerpo desaparecido son categorías micropolíticas que sirven para aprehender la identidad en torno a una construcción política dual: a favor o en contra del régimen.

El proceso del cuerpo expuesto en la tortura niega la imagen de sujeto hasta ese momento creada, dando una conciencia mayor al cuerpo y a su simbolismo mediante la agresión verbal y/o física. Se pretendió hacer una subsunción de toda la personalidad en el cuerpo supliciado.

Recordar la naturaleza carnal del cuerpo es alejarlo de su construcción simbólico-política. Pero si entendemos que precisamente la política es una apropiación de la violencia por parte de cierta autoridad, que la legitima, el acto de usarla en el cuerpo de una persona reconstruye precisamente ese simbolismo. En ese sentido el neoliberalismo logra consenso a través de un medio como es el terror, el miedo y la violencia. Los malos tratos físicos repercuten en los cuerpos torturados y generan dificultades a la hora de recuperar el lugar previo a ellos, tanto a un nivel social, como emotivo y simbólico. Pero ese 
Rev. SINAPSIS, Edición № 9, Vol. 2, Diciembre 2016

ISSN 1390 - 9770

desplazamiento sirve también para empoderar la acción política y luchar contra el régimen que realizó dichos maltratos.

La tortura es consustancial al capitalismo, pero no puede ser absorbida por la historia lineal de Occidente. Debe figurar en ciertos espacios de sombras, opacarse, ha de figurar en los intersticios, en los bordes. La tortura es el ejemplo de un afuera constitutivo una "herida colonial” (Mignolo, 2007), capitalista, aún por cicatrizar.La función principal de la tortura es romper la resistencia del sujeto e incluso su propia identidad. Se trata de cambiar el cuerpo para cambiar de y al grupo. Desde el cuerpo, desde su vulnerabilidad, desde su precariedad (Butler, 2006) y desde su daño se llevan a cabo efectos de dominación, expulsión y exclusión. Pero también desde su interrelacionalidad con otros cuerpos y con lo político, se pueden plantear reivindicaciones de derechos, de justicia y de pertenencia,

\section{Referencias bibliográficas}

Alabarces, Pablo Y Garriga Zucal, José (2008) “El 'aguante?: una identidad corporal y popular”. Intersecciones en Antropología No 9, 2008. Pgs. 275-289

Bajtín, Mijail (1989) "Las formas del tiempo y del cronotopo en la novela. Ensayos sobre Poética Histórica" en Teoría y estética de la novela. Madrid. Taurus.

Bhabha, Homi (2002) El lugar de la cultura. Buenos Aires: Manantial.

Boccia, Alfredo (2010) “Represión política y género en la dictadura paraguaya”. En Pedro, Joana María y Scheibbe Wolf, Cristina (Org., 2010) Gênero, feminismo e ditaduras no conesul. Florianópolis. Ed. Mulheres.

Bourdieu, Pierre (1986) Notas provisionales sobre la percepción social del cuerpo. Materiales de sociología crítica. Madrid: la Piqueta

Chamorro Pérez, Andrea, \& Donoso Alliende, Juan Pablo (2012). Antropología visual y testimonio en la postdictadura chilena. Iconos. Revista de Ciencias Sociales. Año 2012, Nº 42. Pgs. 51-70

Diz, Carlos, (2013) “Políticas del cuerpo y heterotopías del \#15M”. Revista de Antropología Experimental No 13, 2013. Monográfico Etnografías de la Indignación. Texto 5. Pgs. 89-111 


\section{Rev. SINAPSIS, Edición №9, Vol. 2, Diciembre 2016}

Douglas, Mary (1991) Pureza y peligro: análisis de los conceptos de contaminación y tabú. Madrid: Siglo XXI

Durkheim, Émile (1992) El suicidio. Madrid: Akal

Fanon, Frantz (2009) Piel negra, máscaras blancas. Madrid: Akal

Fassin, Didier (2003) “Gobernar por los cuerpos, políticas de reconocimiento hacia los pobres y los inmigrantes en Francia”. Cuadernos de Antropología social N 17. 2003. Pgs. 49-78.

Fiucault, Michel (1990) Vigilar y castigar. Nacimiento de la prisión. Buenos Aires: Siglo XXI

Le Bretón, André (1999) Antropología del dolor. Barcelona: Seix Barral

Le Bretón, André (2002) Antropología del cuerpo y modernidad. Buenos Aires: Nueva Visión

Linebaugh, Peter \&Rediker, Marcus (2005). La hidra de la revolución: marineros, esclavos y campesinos en la historia oculta del Atlántico. Barcelona: Crítica

Kaplan, Temman: "Revertir la vergüenza y revelar el género de la memoria". Publicadooriginalmenteen Signs: Journal of women in Culture and society, Vol 28, Otoño 2002. Pgs. 179-200

Klein, Naomi (2007). La doctrina del shock: el auge del capitalismo del desastre. Barcelona: Paidós.

Marchesi, Aldo \&Markarian, Vania (2012). “Cinco décadas de estudios sobre la crisis, la democracia y el autoritarismo en Uruguay”. Revista Contemporánea, Año 3, Volumen 3, 2012. Pgs. 213-242

Mauss, Marcel (1979) Sociología y Antropología. Madrid: Tecnos

Melgarejo, Romero \& Osvaldo y Pech Matamoros, Alessa (2013) “Las teorías de la violencia en las ciencias sociales: un análisis crítico. En Romano Garrido, Ricardo; Pérez Taylor, Rafael \& Jiménez Guillén, Raúl (2013). Violencia. Poder, imaginarios e incertidumbre. Tlaxcala, México: Universidad Autónoma de Tlaxcala.

Mignolo, Walter(2007). La idea de América Latina: la herida colonial y la opción decolonial. Barcelona: Gedisa. 
Rev. SINAPSIS, Edición № 9, Vol. 2, Diciembre 2016

ISSN 1390 - 9770

Pérez Taylor (2013) "Violencia e imaginarios: estudio sobre el terror” En Romano Garrido, Ricardo; Pérez Taylor, Rafael \& Jiménez Guillén, Raúl (2013). Violencia. Poder, imaginarios e incertidumbre. Tlaxcala, México: Universidad Autónoma de Tlaxcala.

Sapriza, Graciela: “Memorias de mujeres en el relato de la dictadura UUruguay, 1973-1985). Violencial Cárcel/ Exilio. Deportate, esuli, profughe. Revista telemática di estudisulla memoria femminile $\mathrm{N}^{\mathrm{o}} 11$, 2009. Pgs. 64-80

Schepper-Hughes, Nancy (1997) La muerte sin llanto. Violencia y vida cotidiana en Brasil. Barcelona: Ariel

Scott, James C. (2003) Los dominados y el arte de la resistencia. Tafalla: Txalaparta

Sousa Santos, Boaventura (2010) Para descolonizar occidente. Más allá del pensamiento abismal. Buenos Aires: CLACSO

Varela, Cecilia Inés \& González, Felipe: “Tráfico de cifras: ‘desaparecidas” y ¿rescatadas” en la construcción de la trata como problema público en la Argentina” Apuntes de Investigación del CECYP, 2015 (26) Pgs. 74-99 